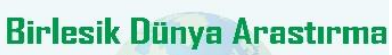 \\ BD-CENTER}

Innovasyon ve Yayıneılık Merkezi

\section{International Journal of Learning and Teaching}

Volume 12, Issue 4, (2020) 166-175

www.ij-lt.eu

\title{
Does work commitment and job satisfaction matter to junior high school teachers in the Philippines?
}

\author{
Rebecca Fullero Averion*, University of Rizal System · College of Social Sciences Philippines \\ Heidi Belle Francisco Caleja, University of Rizal System · College of Social Sciences Philippines
}

\section{Suggested Citation:}

Averion, R. F. \& Caleja, H. B. F. (2020). Does work commitment and job satisfaction matter to junior high school teachers in the Philippines? International Journal of Learning and Teaching. 12(4), 166-175.

https://doi.org/10.18844/ijlt.v12i4.4575

Received June 05, 2020; revised August 10, 2020; accepted October 15, 2020.

Selection and peer review under responsibility of Prof. Dr. Hafize Keser, Ankara University, Ankara, Turkey.

${ }^{\circ} 2020$ United World Center of Research Innovation and Publication. All rights reserved.

\begin{abstract}
This study finds out the relationship between work performance and job satisfaction among teachers of junior high schools in Philippines. They were well aware of the facts of their job satisfaction, e.g., school policies, supervision methods, pay and other benefits, relationships between faculty and students, further growth and promotions, workplace conditions, achievement and recognition, and responsibility and accountability. It was concluded that teachers' job satisfaction could produce an effectiveness and sustainability in educational institutions. Using a descriptive method, a non-probability convenience sampling was employed for 70 public school teachers. Two existing validated questionnaires were used: the Three-Component Model Employee Commitment Survey, to surface the level of work commitment of teachers in an organisation; and Job Satisfaction Survey, to evaluate the teachers' overall job satisfaction. Findings show a significant relationship between work commitment and job satisfaction, specifically in terms of position and educational level. In addition, teachers are satisfied with the people within the organisation; however, it also shows that teachers are not satisfied with too much paper work. It is recommended that teachers should consider the teaching job as a profession and as a vocation.
\end{abstract}

Keywords: High schools in Philippines, job satisfaction, descriptive method, work commitment.

* ADDRESS FOR CORRESPONDENCE: Rebecca Fullero Averion, J.P. Rizal St, Brgy. Sampaloc, Tanay, Rizal, Philippines E-mail address: $\underline{\text { rebecca averion@yahoo.com }}$ 


\section{Background of the study}

The role of teachers is recognised as an essential tool to gain desired results from the students, but offering of such a suitable working environment is left quite neglected (Liang \& Akiba, 2017). Provision of such satisfactory conditions plays a major role in coping with the hurdles and challenges teachers face in their profession. Job satisfaction of the teachers also impacts their students' performance. Furthermore, satisfied teachers offer higher educational quality and suitable learning support for the students could be achieved by providing better job conditions for the teachers. Non-satisfying conditions are also reasons for the shortage of qualified and professional teachers, less job commitment and leaving the profession (Blomeke, Houang, Hsieh \& Wang, 2017). Non-satisfying job conditions directly affect the students' performance, faculty trust and institutional knowledge with overall school performance.

\section{Introduction}

Quality education is one of the best services a government or country can offer. It leads to a better quality of life (Barlongo, 2015). The quality of human resources plays a major role in achieving productive and sustainable goals in increasingly competitive environments of organisations. Human resources are the key elements for any organisation; they contribute significantly in order to increase the performance of the organisation and to bringing out excellence and quality. To know the needs, values and satisfaction of the employees is the fundamental point to raise their level of commitment and loyalty to the organisation. Providing positive working environments and job satisfaction would lead an organisation to gain desired results. On the other hand, negative behaviour and poor services of the disgruntled employees will lead to low-quality results, lack of trust, low morality and vulnerability of the organisations.

Committed, loyal and satisfied employees are necessary for an organisation and their engagement in implementing the institutional goals, plans or targets is at very high level. Organisational culture is also an important aspect in this regard. Organisational values are passed on through teaching, training or by setting an example. For instance, the implementation of different resolutions, researches and recommendations should be practised. Various studies on job satisfaction link it with different measures and factors, e.g., spiritual leadership, school culture, values and beliefs and significance of the workplace in the studies of Peterson (2016) and Matherly and Ouimet (2010); job satisfaction was linked with spiritual leadership.

On the other hand, job satisfaction is also very important for the efficacy of teachers. On the contrary, workload of public school teachers is not only limited to teaching but also to other nonteaching tasks (David, Albert \& Vizmanos, 2019). Additionally, teachers are expected to perform numerous duties at a high level and to take into account various factors in managing their students' learning (Erdogan \& Cavl, 2019). School teachers, stated by every public school, have to engage in at least 6 hours of actual classroom teaching and/or equivalent teaching-related activities and to complete the 8-hour workday, and 2 hours of work inside or outside the school premises are carried out in teaching-related activities (Agpay, 2019). With this issue, there is a discontinuity of reactions pertaining to teacher's experience high levels of stress, exhaustion and low morale while performing work (Llego, 2019).

\section{Literature review}

At the junior high school level in Philippines, most of the educational institutions face difficulties in maintaining the commitment and efficiency of teachers. Due to hostile environments, teachers move out of the system and it causes lack of faculty and low quality of education. This uncertain condition of the faculty's commitment is purely because of low salary and benefits, poor working conditions, low job satisfaction and lack of cachet for the teachers. The researcher explores the level of teachers' 
satisfaction about the job, their job commitment and organisational culture that a faculty possesses in the junior high level schools. The culture of a school can be defined as the behaviours and attitudes of the students and faculty, interaction between faculty and faculty or student and student or faculty and student, the level of school's overall performance and how the school is supportive, engaging, challenging and inspiring to gain the desired results (Elias, 2015). A school's culture revolves around moral values and trust to create a result-oriented and encouraging workplace for students as well as for the teachers and other staff (Peterson 2016). This issue brings an enormous challenge and different studies were conducted in this regard with different factors, conclusions and recommendations. This issue has a crucial position due to its substantial effects and influence on school leaders to meet the desired job satisfaction and gain job commitment from the teachers. Teacher commitment in an organisation is an important issue not only for teachers but also for schools and students (Fantahun, 2019).

Teacher quality and performance issues, including teacher productivity in terms of student outcomes, and teacher attrition, are of great concern to educational researchers and policy-makers (Finster, 2013). In Philippines, teachers have to engage in at least 6 hours of actual classroom teaching and 2 hours equivalent teaching-related activities within and outside of the school to complete the 8-hour workday (Agpay, 2019). The workload of public school teachers is not only limited to teaching but also to other non-teaching tasks (David et al., 2019).

The Three-Component Model (TCM) of Commitment comprises of three distinguishable components: affective commitment (AC), which is an emotional connection that employees have with the organisation; continuance commitment (CC), which is the cost-benefit of leaving the organisation; and normative commitment (NC), which is the employee's feeling of obligation to stay with the organisation. Furthermore, teachers' work commitment is a very crucial issue in the implementation of their vision, goals and mission; hence, inadequate provision of facilities, promotion/growth opportunities, financial benefits and poor leadership resulted in teachers' low commitment in general (Tadesse, 2019).

\section{Significance of the study}

The objective significance of this study is to provide data which could cover the fundamental issues in order to improve the level of commitment and job satisfaction of an organisation. It also aims to give an outlook of the effects of job commitment and job satisfaction on faculty members and the respondent-institutions. Moreover, this study could impart a blue print of a balanced programme that will be beneficial to gather more information for further research.

\section{Research questions}

The following are the basic research questions derived from the organisational theories of the survey:

1. What is the demographic profile?

2. What is the level of commitment of BBEMNHS teachers?

3. What is the job satisfaction level of BBEMNHS teachers?

4. What kind of relationship does exist between junior high school teachers' organisational commitment scale level and their demographical characteristics in terms of age, gender, marital status, educational attainment, position, years in service and subject taught?

5. What kind of relationship does exist between junior high school teachers' job satisfaction and their demographical characteristics in terms of age, gender, marital status, educational attainment, position, years in service and subject taught?

6. Is there a significant relationship between the level of commitment and the job satisfaction level 


\section{Scope and limitation}

This study used two existing validated survey questionnaires - work commitment and job satisfaction - to surface the Guidelines for the Implementation of CSC Resolution No. 080096 on Working Hours for Public School Teachers and to associate which variable is most significant to the policy.

\section{Ethical considerations}

Prior to conducting this study, approval was obtained from Benjamin B. Esguerra Memorial National High School. The researchers gave assurance that all participants would be treated in an ethical manner such as providing a consent form indicating that participation was voluntary. In relation to the Republic Act 10173 also known as 'Data Privacy Act of 2012', the participants were not asked to give their names and surveys were identified by an assigned number to protect the fundamental human right of privacy of communication while ensuring free flow of information to promote innovation and growth. Also, this study adheres to the 'time on task' as per DO 9, S. 2005, so that participants were only allowed to take the survey during their vacant or free hour. Also, request letters of permission to use the two adoptive tools were sent to the authors not only for the truthfulness of the study but also for the fairness of the authorship.

\section{Research methodology}

Using a descriptive method, a non-probability convenience sampling was used for 70 public school teachers from Benjamin B. Esguerra Memorial National High School using two existing validated questionnaires, the TCM Employee Commitment Survey, to surface the level of work commitment of teachers in an organisation; and Job Satisfaction Survey, to evaluate the teachers' overall job satisfaction.

The researchers used the following methods to collect information about issues to solve through analysing and interpreting the data (Salaria, 2012) by statistical treatment:

1. Frequency, percentage and rank: to determine the proportion of the respondent's demographic profile.

2. Mean: to identify the level of agreement of the respondents in terms of TCM Employee Commitment and Spector's Job Satisfaction.

3. Summation: to determine Spector's job satisfaction level.

4. Pearson's correlation: to measure the relationship between teachers' commitment level and teachers' job satisfaction.

The researchers used IBM Statistical Package for the Social Sciences (SPSS) Statistics Subscriptions (Free Trial) for easy computation of data gathered.

\section{Data collection}

The researchers used a survey research with a combination of two existing validated questionnaires. The TCM Employee Commitment Survey is a standardised revised instrument which measures three forms of employee commitment to an organisation. They are AC, NC and CC. It was scored separately to identify the 'commitment profile' of the employee within the organisation. In addition, a 36-item Job Satisfaction Survey (JSS) was used to know how the teachers feel about their job. Meanwhile, the two existing validated surveys had surfaced its significance on DepEd Order No. 16 , s. 2009. For further understanding, teachers' demographical profiles (age, educational attainment, gender, position, years in service and subject taught) were examined to mediate relationships between two variables. 
Table 1. Demographic profile

\begin{tabular}{|c|c|c|c|c|}
\hline Variable & \multirow[t]{2}{*}{ Category } & \multicolumn{3}{|c|}{ FrequencyPercentageRank } \\
\hline \multirow[t]{4}{*}{ Age } & & 23 & 32.90 & 2 \\
\hline & $30-39$ & 30 & 42.86 & 1 \\
\hline & $40-49$ & 13 & 18.60 & 3 \\
\hline & 50-above & 4 & 5.70 & 4 \\
\hline \multirow[t]{2}{*}{ Gender } & Male & 12 & 17.10 & 2 \\
\hline & Female & 58 & 82.90 & 1 \\
\hline \multirow[t]{4}{*}{ Marital status } & Single & 28 & 40.00 & 2 \\
\hline & Married & 40 & 57.10 & 1 \\
\hline & Widowed & 1 & 1.40 & 3 \\
\hline & Separated & 1 & 1.40 & 3 \\
\hline \multicolumn{2}{|c|}{ Educational levelBachelor } & 48 & 68.60 & 1 \\
\hline & Masteral & 21 & 30.00 & 2 \\
\hline & Doctoral & 1 & 1.40 & 3 \\
\hline \multirow[t]{3}{*}{ Position } & Teacher I & 53 & 75.70 & 1 \\
\hline & Teacher II & 13 & 18.60 & 2 \\
\hline & Teacher III & 4 & 5.70 & 3 \\
\hline \multirow[t]{7}{*}{ Years in service } & 3 months-3years & 28 & 40.00 & 1 \\
\hline & & 11 & 15.70 & 4 \\
\hline & 4 years -6 years & 13 & 18.60 & 2 \\
\hline & 7years-10years & 13 & 18.60 & 2 \\
\hline & 11years-15years & 2 & 2.90 & 6 \\
\hline & 16years-20years & 3 & 4.30 & 5 \\
\hline & 21years-25years & & & \\
\hline \multirow[t]{10}{*}{ Subject taught } & English & 12 & 17.10 & 2 \\
\hline & Math & 8 & 11.40 & 5 \\
\hline & filipino & 8 & 11.40 & 5 \\
\hline & science & & & \\
\hline & ESP & & & \\
\hline & Araling panlipunan MAPEH & 9 & 12.90 & 4 \\
\hline & TLE & 3 & 4.30 & 8 \\
\hline & & 7 & 10.00 & 7 \\
\hline & & 13 & 18.60 & 1 \\
\hline & & 10 & 14.30 & 3 \\
\hline
\end{tabular}

The affective commitment scale (ACS) of 70 public school teachers had a score of 5.06 with a verbal interpretation of slightly agree, which implies that employees had a less perception of their emotional attachment to or identification with their organisation.

In terms of the normative commitment scale (NCS), it had a score of 4.38 with a verbal interpretation of undecided, which implies that the respondents were not sure if they were willing to continue working in the organisation.

Lastly, in the continuance commitment scale (CCS), it had a score of 5.22 with a verbal interpretation of slightly agree, which means the respondents had few reasons for the need to stay in the organisation.

The overall respondents' commitment level had a score of 4.89 with a verbal interpretation of slightly agree, which means there is some extent of working with commitment. 
Table 2. Level of commitment

\begin{tabular}{lccll}
\hline \multicolumn{1}{c}{ Variables } & Mean & Std. Deviation & $\boldsymbol{n}$ & V.I. \\
\hline Affective Commitment Scale & & & \\
ACS1 & 5.64 & 0.885 & 70 & Agree \\
ACS2 & 4.79 & 1.559 & 70 & Slightly agree \\
ACS3 & 4.57 & 1.99 & 70 & Slightly agree \\
ACS4 & 4.57 & 1.93 & 70 & Slightly agree \\
ACS5 & 4.91 & 1.894 & 70 & Slightly agree \\
ACS6 & 5.9 & 1.065 & 70 & Agree \\
& 5.06 & 1.55 & & Slightly agree \\
& & CCS & & \\
NCS1 & 4.76 & 1.527 & 70 & Slightly agree \\
NCS2 & 5.39 & 1.572 & 70 & Agree \\
NCS3 & 1.833 & 70 & Undecided \\
NCS4 & 1.17 & 1.609 & 70 & Undecided \\
NCS5 & 3.93 & 1.395 & 70 & Undecided \\
NCS6 & 3.79 & 1.6 & 70 & Undecided \\
& 4.23 & NCS & & Undecided \\
CCS1 & 4.38 & 1.62 & & \\
CCS2 & & 1.667 & 70 & Slightly disagree \\
CCS3 & 3.01 & 1.525 & 70 & Slightly agree \\
CCS4 & 5.06 & 0.889 & 70 & Slightly agree \\
CCS5 & 5.14 & 0.976 & 70 & Agree \\
CCS6 & 6.14 & 0.974 & 70 & Agree \\
& 6.06 & 1.28 & 70 & Agree \\
\hline
\end{tabular}

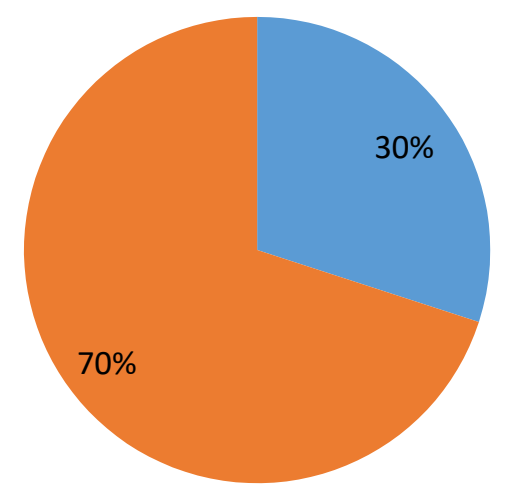

Graph 1. Spector's job satisfaction

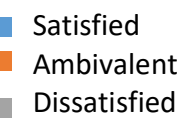

There were 21 out of 70 , or 30\%, respondents who were satisfied and 49 , or $70 \%$, of the respondents who were ambivalent, and no respondents were dissatisfied (see Table 3). Thus, most of the respondents' satisfaction level is equivocal or unclear.

Table 3. The facets of the job satisfaction scale results (JSS)

\begin{tabular}{llcc}
\hline Pay & $\boldsymbol{m}$ & SD \\
\hline 1 & Fair amount paid & 3.59 & 1.39 \\
10 & Raises are not often and low & 4.10 & 0.80 \\
19 & unappreciated by the organisation & 2.80 & 1.12
\end{tabular}


28 Satisfied with salary increases

$4.24 \quad 1.39$

Promotion

2 Little chance for promotion on my job

$3.84 \quad 1.12$

11 Promoted

$4.34 \quad 1.03$

20 Few rewards work

$3.70 \quad 1.03$

33 Satisfied for promotion

$3.84 \quad 1.15$

Total

$3.93 \quad 0.06$

Supervision

3 Supervisor is competent

$4.63 \quad 1.14$

12 Supervisor is unfair to me

2.091 .14

21 Supervisor shows little interest withsubordinates

$2.63 \quad 1.16$

30 I like my supervisor

$4.87 \quad 1.06$

Total

$3.55 \quad 0.04$

Fringe benefits

$4 \quad$ Not Satisfied

$3.73 \quad 1.20$

13 Good Benefits

$3.60 \quad 1.17$

22 Equitable Package

$3.74 \quad 1.09$

29 Don't have what we deserve

$4.63 \quad 1.32$

Total

$3.93 \quad 0.10$

5 Recognition

$3.80 \quad 0.99$

14 Not appreciated

Contingent rewards

23 Few rewards

$3.33 \quad 1.21$

32 No rewards

$3.60 \quad 1.22$

Total

$3.76 \quad 1.06$

3.620 .12

6 Good procedures

Operating conditions

15 My efforts to do best

$3.94 \quad 1.11$

24 Too much workload

$2.76 \quad 1.35$

31 Too much paperwork

$4.60 \quad 1.01$

Total:

$4.87 \quad 1.12$

$4.04 \quad 0.14$

$7 \quad$ l like the faculty members

Co-workers

16 Work harder at my job

$5.13 \quad 0.82$

25 I enjoy with my colleagues

$2.87 \quad 1.23$

34 Too much fuss at work.

$5.11 \quad 0.94$

Total

$2.84 \quad 1.21$

$3.99 \quad 0.20$

Nature of work

8 Job looks meaningless, sometimes

$2.84 \quad 1.38$

17 I like what I do at work

$4.79 \quad 0.74$

27 Too much to do at work

$4.60 \quad 1.01$

35 My job is enjoyable

$4.63 \quad 0.92$

Communication

9 Good communication within organisation. $\quad 4.51 \quad 1.15$

18 Organisational goals are not clear $\quad \begin{array}{lll}2.60 & 1.30\end{array}$

$\begin{array}{llll}26 & \text { Do not know what is going on within the organisation. } & 3.24 & 1.26\end{array}$

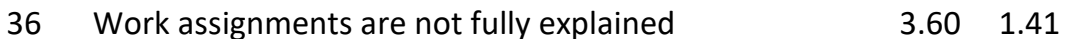

Total

$3.49 \quad 0.11$

Grand Total satisfaction

$3.83 \quad 0.43$


Looking at the mean of the facets in Table 3, participants were ambivalent towards pay (3.68), promotion (3.93), supervision (3.55), fringe benefits (3.93), contingent rewards (3.62), co-workers (3.99) and communication (4.49).

However, participants were satisfied with operating conditions (4.04) and the nature of work, with the highest mean of 4.21 .

Table 4. Relationship between the commitment level of BBEMNHS teachers and their demographic profile (age, gender, marital status, educational attainment, position, years in service and subject taught)

\begin{tabular}{|c|c|c|c|c|c|c|c|c|}
\hline & & Age & Gender & $\begin{array}{l}\text { Marital } \\
\text { status }\end{array}$ & $\begin{array}{c}\text { Educational } \\
\text { level }\end{array}$ & Position & $\begin{array}{l}\text { Years in public } \\
\text { service }\end{array}$ & $\begin{array}{c}\text { Subject } \\
\text { taught }\end{array}$ \\
\hline $\begin{array}{l}\text { Pearson's } \\
\text { correlation }\end{array}$ & 0.003 & -0.013 & -0.066 & 0.143 & 0.038 & 0.056 & -0.047 & \\
\hline \multirow{2}{*}{$\begin{array}{l}\text { Level of } \\
\text { commitment }\end{array}$} & Sig. & 0.978 & 0.913 & 0.590 & 0.239 & 0.753 & 0.648 & 0.698 \\
\hline & $n$ & 70 & 70 & 70 & 70 & 70 & 70 & 70 \\
\hline
\end{tabular}

Table 4 shows that there is a positive relationship between the level of commitment and the demographic profile in terms of age (0.003), educational attainment (0.143), position (0.038) and years in service $(0.0555)$. There is also a negative relationship in terms of gender $(-0.013)$, marital status $(-0.065)$ and subject taught $(-0.047)$.

Table 5. Relationship between the job satisfaction of BBEMNHS teachers and their demographic profile (age, gender, marital status, educational attainment, position, years in service and subject taught)

\begin{tabular}{|c|c|c|c|c|c|c|c|}
\hline & Age & Gender & $\begin{array}{l}\text { Marital } \\
\text { status }\end{array}$ & $\begin{array}{c}\text { Educational } \\
\text { level }\end{array}$ & Position & $\begin{array}{c}\text { Years in public } \\
\text { service }\end{array}$ & $\begin{array}{l}\text { Subject } \\
\text { taught }\end{array}$ \\
\hline Pearson's correlation & -0.181 & -0.052 & -0.170 & 0.024 & -0.149 & -0.192 & 0.250 \\
\hline Job $\quad$ Sig. $n$ & 0.134 & 0.668 & 0.160 & 0.841 & 0.218 & 0.112 & 0.037 \\
\hline satisfaction & 70 & 70 & 70 & 70 & 70 & 70 & 70 \\
\hline
\end{tabular}

Table 5 shows that there is a positive relationship between job satisfaction level and demographic profile in terms of educational level (0.024) and subject taught (0.250). There is also a negative relationship in terms of age $(-0.180)$, gender $(-0.052)$, marital status $(-0.169)$, position $(-0.149)$ and years in public service (0.191).

Table 6. Relationship between level of commitment and job satisfaction level

\begin{tabular}{lc}
\hline Correlations $\quad$ Job satisfaction level \\
\hline CommitmentPearson's correlation $0.230^{*}$ \\
Level $\quad$ Sig. (one-tailed) $n$ & 0.028 \\
& 70 \\
\hline$p \geq 0.05=$ NS and $p<0.05=\mathrm{S}$. &
\end{tabular}

In Pearson's correlation (see Table 6), there were positive correlations between the teachers' commitment level and the teachers' job satisfaction level, which was statistically significant. Thus, as the teachers' commitment level increases, the job satisfaction level also increases and vice versa.

\section{Results and discussion}

The majority of the respondents ranged from 30 years old to 39 years old (42.86\%). Most of the participants were female (82.90\%), married $(57.10 \%)$, graduated with a bachelor degree $(68.6 \%)$, worked as a Teacher I (75.70\%) in the public school, for 3 months to 3 years (40\%) and $18.60 \%$ were in the MAPEH department. 


\subsection{Discussion}

This study investigates the relationships between teacher commitment and job satisfaction, working conditions in schools and other characteristics. It also examined the interactions between the above-mentioned factors in their relation to teacher job satisfaction. Three aspects found significant teacher job satisfaction - student discipline, teacher collaboration and workload. The certainty of a well-planned programme was also examined and the following practices should be adopted to gain better results:

- School premises should be well asserted.

- Workplace should be well groomed and sufficient.

- Materials regarding teaching and learning should be provided accordingly.

- Positive relationship with colleagues and students.

Reasons behind quitting the job or not performing well in school or classroom were that an excessive workload could cause emotional exhaustion and low motivation of the teachers (Skaalvik and Skaalvik 2016). Teacher cooperation and characteristics, school's social climate, supportive relationship between students and teachers and well-established workplace play a crucial role to build a significant and effective system not only in schools but also in the whole education sector. Student discipline is another aspect of teacher satisfaction as it was already researched and affirmed (Ingersoll, 2017; Sims, 2017).

\section{Conclusion}

This study discloses that the junior high school teachers' CCS score shows that teachers tends to stay in the organisation because they need and have to. Meanwhile, the ACS implies that even if teachers thought that they need to stay in the organisation they still have an emotional attachment and have a great deal of personal meaning within the organisation. However, although teachers owe a great deal of personal meaning within the organisation, they were unsure of continuing to work in it.

With regard to Spector's job satisfaction, the researchers concluded that majority of the public junior high school teachers were ambivalent or otherwise moderately satisfied in their job in terms of pay, promotion, supervision, fringe benefits, contingent rewards, co-workers, and communication. Meanwhile, 2 out of 10 facets, namely operating conditions and nature of work, scored satisfactorily, which means that even if they have much work to do, they do not find their job meaningless and they still enjoy it.

\section{References}

Agpay, E. J. (2019). A teacher's workload. Naga, Philippines : Bicol Standard. Retrieved September 7, 2019, from http://www.bicolstandard.com/2019/04/teacher-corner- teachers-workload.html

Barlongo, C. J. (2015). Reforms in the Philippine education system: the $K$ to 12 program. Manila, Philippines: Business Mirror. Retrieved 26 May from https://businessmirror.com.ph/reforms-in-thephilippineeducation-system-the-k-to-12-program/

Blomeke, S., Houang, R., Hsieh, F. J. \& Wang, T. Y. (2017). Effects of job motives, teacher knowledge and school context on beginning teachers' commitment to stay in the profession: a longitudinal study in Germany, Taiwan and the United States. In G. K. LeTendre \& M. Akiba (Eds.), International handbook of teacher quality and policy (pp. 374-387). Abingdon, UK: Routledge.

David, C. C., Albert, J. R. \&Vizmanos, J. F. (2019, February). Pressures on public school teachers and implications on quality. Quezon City, Philippines: Philippine Institute for Development Studies.

Elias, M. (2015). You need an elevator pitch about school culture and climate. Retrieved February 19, 2016, from http://www.edutopia.org/blog/youneed/elevator- pitch-about-school-culture-and-climate maurice-elias 
Erdogan, E. \& Cavl, E. (2019). Investigation of organizational commitment levels of physical education and classroom teachers. Universal Journal of Educational Research, 7(1), 259-265. doi:10.13189/ ujer.2019.070133

Ingersoll, R. (2017). Misdiagnosing America's teacher quality problem. In G. K. LeTendre \& M. Akiba (Eds.), International handbook of teacher quality and policy (pp. 79-96). London, UK: Routledge.

Jackson, C. (2018). Relationships between job satisfaction, Organizational Commitment, and Teacher Engagement. Minneapolis, MN: Walden University.

Liang, G. \& Akiba, M. (2017). Teachers' working conditions: a cross-national analysis using the OECD TALIS and PISA data. In G. K. LeTendre \& M. Akiba (Eds.), International handbook of teacher quality and policy (pp. 388-402). New York, NY: Routledge.

Llego, J. H. (2019, July). Central Luzon State University, Sigma's 30th International Nursing Research Congress.

Matherly, L. L. \& Ouimet, J. (2010). The spiritual leadership balanced scorecard business model: the case of the Cordon Bleu-Tomasso Corporation. Journal of Management, Spirituality and Religion, 7(4), 283-314. doi.org/10.1080/14766086.2010.524983

Sims, S. (2017). TALIS 2013: Working conditions, teacher job satisfaction and retention (Department for Education Statistical Working Paper). London, UK: Department of Education.

Tadesse, E. F. (2019). Teachers' organizational commitment at secondary school in Addis Ababa, Ethiopia. International Journal of Education and Research, 53-68 